\title{
La pérdida de distinción fonológica /j/ - / / en el habla bogotana
}

\author{
The loss of the phonological distinction /j/ - / K/ in the \\ Bogotanian speech
}

Yehicy Orduz Navarrete ${ }^{1}$

\section{Resumen}

Los estudios dialectales en Colombia han generado gran interés, ante todo, a partir de los años 70. Dialectólogos nacionales como Flórez y Montes, y sus muchos alumnos, han procurado dar cuenta del español colombiano en cientos de artículos publicados en revistas nacionales y extranjeras.

Continuando con esa visión y tomando como fundamento el hecho de que la evolución lingüística inicia en el habla, y se confirma en la producción fonética de los individuos que conforman el grupo social, este escrito busca establecer el estado de la distinción fonológica entre $/ \mathrm{j} /-/ K /$, con el fin de validar o revalidar las ideas de estudiosos como José Moreno de Alba, John Lipsky o incluso José J. Montes. La revisión de la literatura acerca del origen de la diferencia y el estudio de su caracterización acústica permitirán establecer el fundamento teórico al análisis de muestras tomadas del habla bogotana. Los resultados permiten describir el estadio de la pérdida de dicha distinción fonológica.

\section{Palabras clave:}

Español de Colombia, habla bogotana, yeísmo, variación fonológica.

Abstract

In Colombia, dialectal studies are of great interest, especially since the 70s. National dialectologists such as Professor Luis Flórez and Professor Jose Joaquin Montes, and many of their students have published several articles about the Spanish spoken in Colombia, in national and international magazines. Following the idea that linguistic evolution starts with speech and is reinforced in the phonetic production in individuals belonging to a social group, this study shows the latest condition of phonological distinction $/ \mathrm{j} /-/ \Lambda /$, with the aim of validating the ideas of experts like José Moreno de Alba, John Lipsky or José J. Montes. The review of theories including origins of difference and the study of their acoustic characterization establish a theoretical foundation for the analysis of some samples of speech from Bogota. The results describe the loss of this phonological distinction.

Keywords:

Colombian Spanish, Bogota's speech, Yeismo, phonological variation.

Artículo recibido el 15 de mayo de 2012 y aprobado el 8 de febrero de 2013

1 Universidad Pedagógica Nacional, Bogotá, Colombia. Correo electrónico: yorduz@pedagogica.edu.co 
"Assí, el hablar y escriuir, aunque nos parezca que está corrompido y alterado de lo que fue en su principio, sea el que fuere, se a de tener por bueno, porque la costumbre y vso lo tiene por tal aprouado."

Bartolomé Jiménez Patón

Para muchos interesados en el estudio de las lenguas, la innovación, como fundamento del cambio lingüístico -fonético, semántico o morfológico-, evidencia un proceso de adecuación expresiva en curso que, algunas veces, termina en la modificación del sistema (cf. Aráus, 2005, pp. 19-51). Esta alteración, perceptible en los planos sincrónico y diacrónico de la lengua, es propia de todos los sistemas lingüísticos; Coseriu lo confirma (1988, citado por Montes, 1995, p. 30) al plantear la mutabilidad como característica esencial y necesaria, que refleja la transformación ininterrumpida de una sociedad unificada por aquellos.

Ante este hecho el español colombiano no es inmune; una muestra clara se tiene con la correspondencia $/ \mathrm{j} / \mathrm{-} / \mathrm{K} / 2$. Si tenemos en cuenta posiciones como la de Moreno de Alba (1988, p. 155), quien caracteriza el habla de Colombia por un rasgo peculiar regional: "la pervivencia del fonema lateral [ $\Lambda$ ]", y la de John Lipski (1994, p. 29), quien de manera más evidente especifica que "el fenómeno del yeísmo solo puede observarse en las zonas costeras y orientales colombianas, y no está presente en su zona andina", no habría lugar a preguntarnos por el estado de tal distinción en el país.

Sin embargo, y al contrario de lo que dicen las voces de los grandes hispanistas, si como docentesinvestigadores interesados escuchamos hablar de manera cotidiana no solo a las personas provenientes de diferentes regiones del país, sino en especial a los habitantes de la zona andina cundinamarquesa, sobre todo a aquellas de no muy avanzada edad, podemos percibir que el yeísmo es un fenómeno casi generalizado y que el contraste fonológico /j/ - / / / no existe más que en un delimitado número de casos.

2 La pérdida de la distinción $/ \mathrm{j} /$ - / $/ \mathrm{K}$ es un fenómeno fonológico que genera una simplificación del sistema español, en donde se tiende hacia la pérdida del fonema palatal lateral (deslateralización) y la prevalencia del palatal fricativo. Esta nivelación origina el proceso fonológico conocido como yeísmo.
Tales observaciones nos llevan a preguntarnos: ¿es el yeísmo un fenómeno fonológico ya extendido en el habla bogotana o hay aún pervivencia de la distinción? El cuestionamiento se hace interesante, porque el yeísmo es un fenómeno que ha llamado la atención de varios estudiosos de la lengua por ser característico de buena parte del cambio que se lleva a cabo en el español general, y un estudio actualizado al respecto, será muy enriquecedor pues verificaría el estado actual en el sistema colombiano. Así entonces, el presente escrito dará cuenta de un trabajo dialectal que busca revalidar la pervivencia de la distinción fonológica /j/ - / / / entre los habitantes de Bogotá, con el objeto de contrastar las palabras de Moreno de Alba y Lipski. Los resultados aportarán nuevos datos al estudio dialectológico del español de Colombia y, además, presentarán una continuidad a las reflexiones que el profesor José J. Montes inició cuando en 1969 se preguntaba: “Desaparece la $l l$ de la pronunciación bogotana?”.

\section{Fundamentación teórica de la nivelación fonológica $/ \mathrm{j} / \mathrm{-} / \mathrm{K} /$}

\section{Proveniencia de cada fonema en la lengua española}

Antes de examinar detenidamente el origen de /j/ y $/ K /$, es importante tener presente que en las lenguas indígenas precolombinas de la familia muisca, los sonidos de los fonemas en cuestión no se encontraban de ningún modo. Aunque los aborígenes del territorio chibcha no constituían una masa unilingüe, al consultar las gramáticas existentes, entre las cuales están la de Fray Bernardo de Lugo y aquella de autor anónimo sobre la que María Stella González (1987) trabajó, podemos colegir, apoyándonos en el trabajo de Constenla (1984, p. 82) que, entre otras características fonéticas de la lengua chibcha se encuentra "la ausencia de de las consonantes $d$, $\kappa, r, r, l, j$.

Fonema/K/. Según Miguel A. Caro (1972, p. 43), en latín clásico no existía un sonido correspondiente al grafema ll. Aún así, según Rafael Lapesa (2008, p. 625), el fonema palatal lateral sonoro pudo ori- 
ginarse por varias vías. En primer lugar se tiene un refuerzo de la $l$ inicial que, equiparada con la consonante doble $1 . l$ interior, da en unas áreas resultado palatal y en otras, cacuminal; en segundo lugar, en la reducción del grupo /ld/; en tercer lugar, en la evolución, aunque no generalizada, de los grupos /k'l/, /l'll, /t'll y /1+yod/; en cuarto lugar, en la evolución de los grupos iniciales latinos /pl/, /kl/, /fl/; y en quinto lugar, las vocales /ĕ/ e / $/ \mathbf{1}$ átonas convertidas por el diptongo en semiconsonantes, originaron el fenómeno de yod que, al fundirse con la consonante $l$ que las precedía, la palatalizaron.

Para Coloma Lleal et al. (2000), el fonema / $/ /$ iniciaría su aparición hacia el periodo visigodo (s. V-VII) con la palatalización de sonantes simples, por ejemplo: [álju>aKju> áxo]; y continúa en el romance castellano primitivo (s. VIII-XII) con la palatalización de sonante larga, por ejemplo: [lál:u>láKu>láKo] y con la palatalización de líquida, es el caso de [pláno> pKáno $>$ Káno].

Fonema /j/. También Miguel A. Caro explica que en latín clásico tampoco existía este sonido, aunque sí el grafema y, que se utilizaba para representar en muchos casos, la vocal $i$. Ahora, según Lapesa (2008, p. 640), este fonema también pudo haber evolucionado por varias vías. En primer lugar, y como en el anterior, un refuerzo de la $l$ inicial que, equiparada con la consonante doble $1 . l$ interior da, en unas áreas, resultado palatal y en otras, cacuminal; en segundo lugar, la reducción de los grupos /d+yod/ y/g+yod/; y en tercer lugar, también como en el anterior, en la evolución, aunque no generalizada, de los grupos /k'l/, /l'1/, /t'll/ y /l+yod/.

Para Coloma Lleal et al. (2000), el fonema /j/ aparecería en el castellano medieval (s. XIII-XIV) con la consonantización de yod, por ejemplo: [jélmo>jélmo]; y en el español moderno (s. XV$\mathrm{XX}$ ) con la deslateralización de la palatal, como: [láKo >lá/j/o].

Estudios fonético-fonológicos de los fonemas $/ \mathrm{j} / \mathbf{y} / K /$. Tomando como punto de partida los estudios hechos por Quilis (1988, pp. 220-228 y 281-282), tenemos:

- Caracterización acústica de la palatal fricativa, $/ \mathrm{j} /$ : los sonidos fricativos tienen como característica principal la fricción que produce el aire al pasar a través de la estrechez formada entre dos órganos articulatorios -lengua y paladar-; en el plano de la fonética fisiológica reciben el nombre de constrictivos pues estos dos órganos se constriñen limitando la salida del aire. El momento más perceptible de una consonante fricativa se encuentra en su tensión, que es el más importante tanto acústica como articulatoriamente. Además, infiere en los formantes de las vocales contiguas mostrando ciertas transiciones.

Las consonantes fricativas presentan en español dos grupos claramente delimitados: a) las que poseen predominio de resonancias en las zonas de bajas frecuencias, y b) las que poseen resonancias en las zonas de altas frecuencias u ocupan todo su espectro.

Si la /j/ se encuentra entre las fricativas de resonancias bajas, se tiene una caracterización por ubicación de las zonas de resonancia situadas, principalmente, en la mitad inferior de su espectro. Presentan un grado de estrechamiento que no llega en ningún caso a la fricación llamada rehilamiento. En ellas se pueden observar: a) un F1 (formante 1) mucho más bajo que el de las vocales contiguas; $b$ ) un F2 más débil que el de las vocales; c) la lentitud de las transiciones; d) la fuerte transición positiva del F2. Para finalizar, el fonema /j/ se clasifica acústicamente, según los rasgos binarios de Jakobson y Halle (1980), en compacto, agudo, mate, oral, continuo y sonoro.

- Caracterización acústica de la líquida lateral, / $\mathrm{K} /$ : los sonidos líquidos se llaman así debido a que en ellos existen ciertas características que les infieren una fisonomía intermedia entre los sonidos vocálicos y los consonánticos. Desde el punto de vista articulatorio, presentan una abertura global mayor de la cavidad supraglótica, pese a que en algún lugar de esta cavidad la lengua puede presentar algún obstáculo a la salida del aire. Acústicamente, poseen rasgos vocálicos y consonánticos, ya que como vocales solo tienen una fuente armónica, y como consonantes, aparecen zonas de antirresonancia en su espectro. La estructura formántica de las líquidas es muy similar a la de las vocales, pero 
difiere de estas en que la frecuencia del fundamental y su intensidad global son menores.

El fonema $/ K /$ tanto en posición inicial como medial, presenta las siguientes características: a) un F1 por lo general situado de forma independiente, por debajo del F1 de la vocal que forma su núcleo silábico; muchas veces se produce incluso un espacio entre ambos; b) la intensidad del F1 de la lateral es también menor que la de la vocal acompañante; c) un F2 situado siempre a mayor frecuencia que los homólogos de /a/, /o/, /u/ variando su situación con /i/, /e/. Este F2 tiene poca fluctuación frecuencial y además anticipa el comienzo del F2 de su vocal núcleo silábica; d) las transiciones del primer formante son siempre negativas, y las del segundo son siempre positivas; e) su intensidad es siempre menor que la de su vocal núcleo silábica. Finalmente, el fonema / $/$ / se clasifica acústicamente, según los rasgos binarios de Jakobson y Halle (1980), en vocálico, consonántico, continuo y compacto.

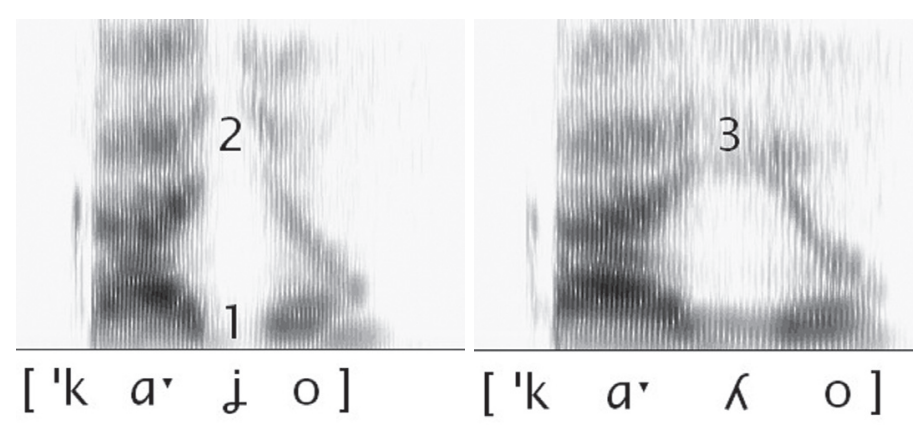

Imagen 1. Sonogramas resultantes de la producción fonética de cayo y callo, creados para ilustrar las observaciones.

-Comparación entre /j/ y /K/ (imagen 1). Para Quilis (1988, p. 288), al comparar la lateral palatal sonora $/ \mathrm{K} /$ con la fricativa palatal sonora $/ \mathrm{j} / \mathrm{se}$ observa: 1) el primer formante de la fricativa tiene menos intensidad y está a menor frecuencia, por lo que aparece con un carácter marcadamente consonántico; 2) normalmente, hay discontinuidad en los formantes altos de la fricativa con una interrupción, o, cuando menos, una pérdida muy elevada de la intensidad en estos formantes; 3 ) como es lógico, a medida que disminuye la constricción, la líquida disminuirá la discontinuidad o elevará su intensidad.

\section{Origen de la desfonologización: el yeísmo.}

Como evidenciamos en la Proveniencia de cada fonema en la lengua española, según Lapesa (2008, pp. 625 y 640), el origen de los fonemas /j/ y / K/ tiene dos fuentes similares: la evolución, aunque no generalizada, de los grupos /k'l/, /l'll, y /l+yod/ y el refuerzo de la $l$ inicial que, equiparada con la consonante doble $l \cdot l$ interior, da resultado palatal o cacuminal. Este hecho nos permite pensar, a manera hipotética, que la semejanza entre las fuentes de procedencia es el germen de la aproximación entre uno y otro sonido, y que con el tiempo, dicha afinidad se ha ido configurando en uniformidad.

Varios trabajos describen el registro de los casos más tempranos de yeísmo (especialmente en España), en las primeras décadas del siglo XVI. Es el caso de Guillermo Guitarte (1983), quien en el artículo titulado "Notas para la historia del yeísmo", hace un balance de la cuestión, y utiliza los aportes previos y las novedades con las que él mismo contaba, para fundamentar sus evidencias del uso temprano de la confusión hacia el yeísmo. Refiere que:

- En el cancionero manuscrito de Pedro del Pozo (1547) se encuentra una versión de las soeces segundas Coplas del Provincial; al copiarlas, el compilador incurre por dos veces en cacografías yeístas.

- En las Cartas privadas de Puebla del siglo XVI, hay dos que pertenecen a Sebastián de Pliego; están fechadas en esta ciudad a marco de 1581. Las cartas revelan una persona de muy escasa cultura en donde se encuentran siete casos de yeísmo. Por sus ideas y por su sintaxis, las cartas caracterizan a Pliego como un hombre del pueblo, al que no falta algún vulgarismo fonético, apareciendo su uso yeísta en un contexto de popularismo o vulgaridad.

- Amado Alonso cita dos poemas de finales del siglo XVII, del escritor peruano Juan del Valle y Caviedes, para establecer la cronología del yeísmo en América. De sus estudios se pudo constatar que el yeísmo era la pronunciación corriente de la población nativa de Lima y la distinción correspondía probablemente a los peninsulares que vivían en ella. 
Tales documentaciones nos llevan a confirmar que la uniformidad proviene de una fuente histórico-geográfica peninsular que arribó a América con los colonizadores, pero en especial, con los andaluces. En España continuó su evolución como se ve en las investigaciones hechas por Navarro (1964) quien publica un artículo resumiendo sus hallazgos en la península:

Se considera como causa general del yeísmo la antigua y persistente tendencia al ablandamiento articulatorio que ha ejercido tan extensa influencia en las lenguas y dialectos romances. Existen en la Península tres focos de yeísmo, independientes entre sí: el asturiano-leonés, el catalán-balear y el andaluz. La única zona peninsular exenta de yeísmo es la del gallego-portugués (p. 13).

En esa misma línea está Ocampo (1978), quien cita estudios que demuestran una base lingüística del español americano en el porcentaje de colonización que, hacia finales del siglo XVI, registraba $42,5 \%$ de emigrantes españoles procedentes del sur de España (Andalucía y Canarias) y 41,7\% de Castilla; el resto, de otras regiones como Extremadura, Cataluña, Navarra, Galicia, Asturias y Vascongadas. Esta leve diferencia porcentual y varios documentos de diversos autores apoyan la hipótesis del origen andalucista del español americano y, por extensión, del bogotano, aunque haya también trabajos que defiendan lo contrario. A este respecto, José J. Montes (1995) anota:

Puede darse por generalmente aceptado en la actualidad un relativo predominio del andaluz (entre las variedades regionales del español) en la primera época de la conquista y colonización. Pero debe rechazarse la identificación del español de América en su conjunto con el andaluz. Pues, como lo han señalado muchos estudiosos, hay en América una zona -coincidente grosso modo con el Caribe insular, las costas y tierras bajas-. En donde la similitud con el andaluz es muy grande, mientras que para el resto del continente -en general tierras altas, regiones interiores- tal similitud se reduce al unos cuantos rasgos (seseo, yeísmo, voseo, etc.) (p. 152).

\section{La pérdida de la distinción en Colombia}

Con respecto a la presencia del yeísmo en Colombia, tenemos varios estudios, en especial, un nuevo trabajo de Montes (1992) en el que comenta su posible origen:

Creo que la situación que describía Cuervo a finales del siglo pasado con yeísmo en las costas y la zona centro-occidental corresponde al español originariamente introducido en Colombia que traía el yeísmo de la zona antillana. Y habrá que repetir que la zona distinguidora (fundamentalmente el dialecto andino oriental) es producto de colonización relativamente tardía, de probable predominio centro-norteño y del español cortesano (pp. 512-513).

Precisamente, Rufino J. Cuervo (1955), como precursor en la referencia de dicha distinción, reseña el principio de tal pérdida como una confusión:

740. Siendo la $l l$ una $l$ palatalizada, se distingue principalmente de la $y$ en la vibración lateral de la lengua, diferencia no muy considerable que fácilmente desaparece ocasionando la confusión de las dos letras. La pronunciación correcta de la $l l$, como se oye en Castilla la Vieja, es rara en Madrid, en Toledo, en Extremadura, en Andalucía y en la mayor parte de América, pues se acerca considerablemente al sonido de la $y$ o se iguala completamente con ella. Por lo que hace a Colombia, en Bogotá y buena parte de lo interior es la $l l$ bien y oportunamente pronunciada, al paso que en Antioquia y lugares de la costa es exclusiva la $y$. En algunos puntos se oye tal cual vez no se valla, Popallán, cosa que también sucede en algún lugar de Extremadura. Los bogotanos no cometemos otro pecado que confundir rallar, rallo, con rayar, rayo, pronunciando con $y$ "rallar pan o queso con un rallo" lo mismo que "rayar con un lápiz el papel" y "caer rayos y centellas" (pp. 526-527).

También se tiene el trabajo de Luis Flórez (1978) quien, entre 1948 y 1978, realizó ciertas observaciones que le permitieron concluir:

94. Consonante y. Es generalmente fricativa, de timbre suave. En casos de pronunciación enfática tiene un refuerzo que la hace africada y la ensordece un poco, sobre todo en sílaba acentuada, ma- 
yormente al comienzo de la palabra. Fácilmente se pueden oír $y$ rehilada y $y$ africada, ensordecidas en muchos lugares y a diversas personas, pero no de manera sistemática.

95. Consonante $l$. En Colombia se da frecuentemente $l l$ del tipo castellano en lugares y hablantes de las siguientes áreas: al sur, particularmente la zona del nudo o macizo de los Andes, cuando aún estos no se han dividido en tres ramas; de este nudo hacia el norte, por la rama o cordillera central, en diversos lugares de la franja oriental del departamento del Cauca; por el sureste, a lo largo de la rama o cordillera oriental: en general y principalmente las tierras altas de los departamentos de Cundinamarca, Boyacá, Santander y Norte de Santander. No obstante, el área de $l l$ castellana en todas esas tierras altas no es homogénea, uniforme y continua, pues se interrumpe aquí y allá con islotes de yeísmo, es decir, de $l l$ pronunciada como $y$ fricativa, así como de pronunciaciones mixtas o intermedias. Tal ocurre, por ejemplo, en los departamentos de Nariño, Cauca, Huila, Tolima, Cundinamarca, Boyacá, Santander y Norte de Santander. Según nuestra experiencia, las tierras altas de Boyacá y Santander ofrecen hoy en Colombia las zonas más amplias y homogéneas de $l l$ castellana (o muy parecida). En la mayor parte del territorio colombiano se pronuncia la $l l$ como $y$. En Bogotá y poblaciones aledañas mucha gente articula hoy $l l$ de tipo castellano, pero en las mismas localidades son también muy numerosas las personas, especialmente jóvenes, que la pronuncian como $y$. En diversos lugares es posible oír a personas que en unas palabras pronuncian $l l y$ en otras $y$ (pp. 220-221).

De acuerdo con lo anterior, Montes (1975) describe las observaciones hechas a partir de la recolección de muestras y la estructuración del ALEC:

4. En el curso de las encuestas para el Atlas Lingüístico-Etnográfico de Colombia (ALEC) he encontrado que en ciertas zonas donde la distinción fonológica entre lly $y$ está en crisis se articula a veces en vez de la africada palatal lateral $/ K /$ un sonido lateral palatalizado pero sin contacto de la lengua con el paladar, que podría representarse con l'. Creo que para estudios dialectales en zonas de $l l$, y sobre todo en regiones limítrofes con otras alodialectales, sería conveniente tener presente la posibilidad de este alófono que parece representar un primer paso (la desafricación o aflojamiento) en el proceso que lleva a la fusión de los fonemas /j/ y /K/ (pp. 130-131).

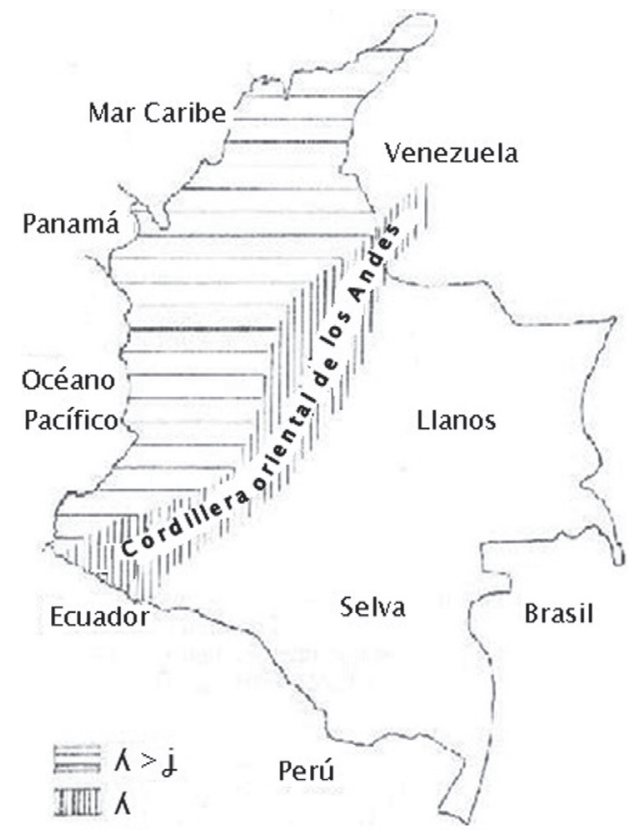

Imagen 2. Zonas de uso /j/ - / $/ /$ en Colombia.

Las pesquisas relacionadas con la elaboración del ALEC permitieron que Montes (1976, p. 190) realizara una zonificación que ilustra muy bien la situación del yeísmo/lleísmo en Colombia (imagen 2). Allí vemos claramente que en las zonas altas de la cordillera oriental se encuentra presente el fonema / $K /$ que, en el resto del país, cede terreno hacia la /j/.

Finalmente, un poco más cerca de nuestra problemática, encontramos dos trabajos también de Montes (1963) que abordan la pronunciación de la $l l$ en Bogotá; en el primero se expone:

Ya se sabe que la $l l$ es un fonema sumamente inestable y que en el mundo hispanohablante los individuos que distinguen $l l$ y $y$ están hoy en franca minoría frente a los igualadores. Más aún, con las noticias, repetidas en los últimos años, sobre la penetración y extensión del yeísmo en Madrid, apenas quedan grandes ciudades de habla española que practiquen la distinción tradicional. Tal vez la ciudad más importante de las que se siguen considerando como mantenedoras 
de la distinción es Bogotá. ¿Corresponde aún tal imagen a la realidad y seguirá correspondiendo en lo futuro? Parece que no (p. 101).

Veintidós años después, luego de tomar 40 muestras a diversos hablantes en Bogotá, Montes (1983), preocupado siempre por la cuestión, señala:

Basándonos fundamentalmente en las dos muestras (1969 y 1983), podemos predecir, casi sin ningún temor a errar, que en el curso de veinte o treinta años, como quien dice a comienzos del siglo XXI, la $l l$ habrá desaparecido totalmente del habla bogotana o será en ella una antigualla rarísima (pp. 295-296).

Cerrando el apartado con esta visión, podemos afirmar que la pérdida de la distinción fonológica existente entre /j/ y / $/$ / surgió como resultado de la práctica comunicativa de los hablantes españoles de la baja Edad Media y se ha ido extendiendo por toda Latinoamérica; la nivelación que conlleva la caída de la palatal lateral, es entonces el resultado de la cercanía articulatoria de los dos fonemas, produciendo la desfonologización (yeísmo) de la lateral junto con la potencial pérdida de su función fonológica.

\section{Reseña sobre la ciudad capital, Bogotá D.C.}

\section{La Bogotá de hoy: población}

Según datos de entidades oficiales como el Departamento Administrativo Nacional de Estadística (DANE) (2010), la Bogotá que conocieron los autores colombianos citados supra, está bien lejos de ser la que es hoy. Es la única ciudad en Colombia que puede llamarse metrópoli pues es sede de los gobiernos nacional, departamental y distrital; según la Fundación Foro Nacional por Colombia (FNC, 2006, p. 14), la capital tiene una elevada participación en el PIB nacional -equivalente a 21\%-, concentra un alto índice de empleos públicos de alto nivel y recibe gran parte de la inversión extranjera, al ser el centro de las operaciones financieras y bursátiles del país.

De manera general, según el Censo de 2005 (DANE, 2010), la población de Bogotá ronda los 6.778.691 habitantes $-61,87 \%$ más que al censo de
1985 (a 2012, se proyectan cerca de 7’500.000 habitantes)-. De ellos, 52,2\% son mujeres y el grupo etario con mayor porcentaje en la población son los adultos jóvenes, entre los 20 y 30 años. En cuanto a escolaridad, 4,1\% no tiene nivel educativo alguno, $27 \%$ ha alcanzado la básica primaria; $36,7 \%$ ha alcanzado la secundaria y $22,1 \%$, un nivel de educación superior y posgrado.

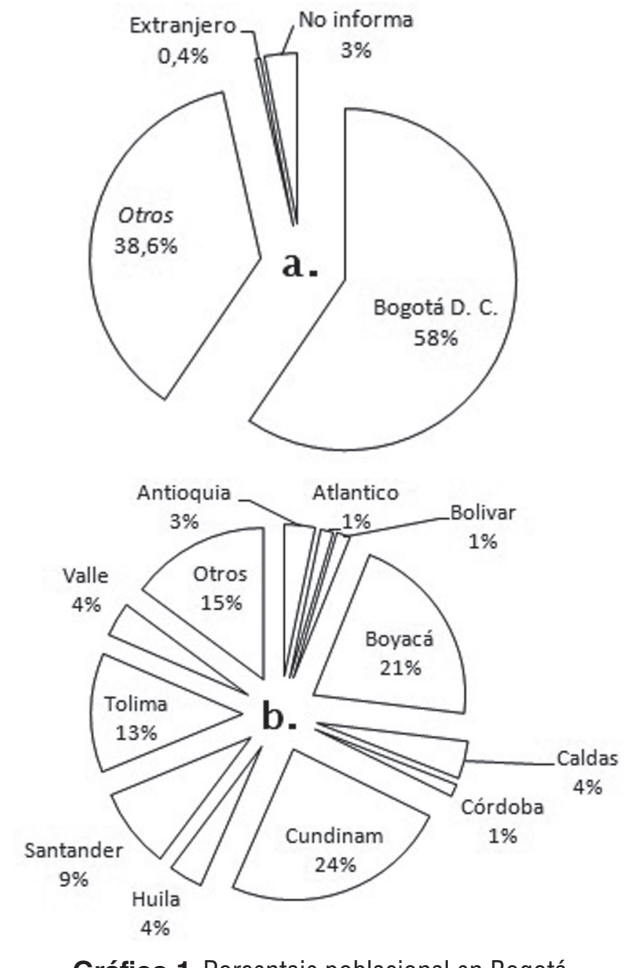

Gráfico 1. Porcentaje poblacional en Bogotá.

a. Porcentaje de pobladores bogotanos y foráneos.

b. Porcentaje analítico de Otros pobladores de Bogotá D. C.

Sumado a lo anterior se tienen otros datos importantes; aunque hubo una disminución de las tasas de crecimiento poblacional, la representatividad está en los estratos 2 y 3 que han aumentado hasta en un $50 \%$ su población. Tal cifra nos permite pensar en un proceso de transformación social que surge en especial de la periferia: Bosa, Ciudad Bolívar, Fontibón, Suba, Usme y Kennedy, localidades donde se han asentado (FNC, 2006, p. 15).

Sin embargo, no debemos contemplar que este aumento del espectro social se deba solo a un aumento en la tasa de natalidad. Según el DANE (2010, 
p. 4), 38,6\% de la población bogotana nació fuera de la ciudad (gráfico 1) y se encuentra establecido en ella por múltiples causas. El desplazamiento forzado presionado por el conflicto interno, la falta de oportunidades laborales y sociales en los sitios de origen, razones familiares y la necesidad de educación, son algunos de los motivos más reiterativos en el proceso de migración hacia la ciudad.

\section{Escenario lingüístico de Bogotá en cuanto a la problemática en cuestión}

No hay en el momento ningún documento que nos permita conocer objetivamente cuál es el estado lingüístico en el que se encuentra la capital hoy ni la influencia que ha tenido la inmigración en el habla. Sin embargo, en 1998, 1999 y 2005 se publicaron tres documentos que surgen de diversas investigaciones acerca del habla bogotana y que pueden marcar interés para la temática que estamos abordando. El primero, de Mariano Lozano (1998), refiriendo el proyecto nacional titulado "El español hablado en Bogotá", en donde describe los logros alcanzados luego de su inicio en 1987. Se relacionan las encuestas, tomadas entre los años 1990 y 1992; los avances publicados, uno en 1997 titulado El español hablado en Bogotá: relatos semilibres de informantes pertenecientes a tres estratos sociales, y el otro en 1998 titulado El español hablado en Bogotá: análisis previo de su estratificación social; y los proyectos por publicar, que relacionarían los materiales léxicos y el análisis fonético. En su escrito, hace una brevísima referencia a los elementos en cuestión diciendo: "El yeísmo sigue imponiéndose y la distinción de / $/ \mathrm{y}$ y /ll/ (sic.) se mantiene en los mayores" (p. 735).

En segundo y tercer lugar, tenemos dos textos de Bernarda Espejo (1999 y 2005). En el más antiguo encontramos algunas observaciones hechas a partir del vocabulario recogido entre 1973 y 1980, para el proyecto de estudio coordinado de la norma lingüística culta de Bogotá (iniciado por el Instituto Caro y Cuervo en 1972). En sus líneas refiere en especial, la mayor frecuencia de uso del fonema $/ K /$ entre hombres y el predominio de su uso en informantes mayores (de 36 años en adelante), mientras que en los jóvenes tuvo baja frecuencia.
En cuanto a la /j/, anota que es relevante su uso por parte de las mujeres y el predominio en jóvenes; en cuanto al yeísmo, resalta su presencia en todos los grupos etarios aunque con menor porcentaje en los hablantes de más edad.

En el documento de 2005, la investigadora expone lo que fue, es y será el español bogotano. Entre lo que nos puede interesar tenemos las referencias a:

a. El uso de la distinción /j/ - /K/en la Bogotá antigua.

b. La casi pérdida del fonema $/ K /$ en pro del fonema / $\mathrm{j} /$ en el español actual.

Es sugerente que, en concordancia con lo mencionado anteriormente, Espejo (2005) indique que el español bogotano, "está sometido a las múltiples transformaciones y cambios ocasionados por factores como el creciente aumento de población, producto de la inmigración de gentes de otras regiones" (p. 209). De igual forma señala, al referir el futuro del español hablado en Bogotá, un abandono de los buenos usos debido a la influencia de los medios de comunicación que recurren a un estilo informal y coloquial; una afirmación que nos lleva a pensar, no solo en la generalización de la pérdida de la distinción -pues hay quienes consideran a los medios de comunicación como un modelo lingüístico a seguir (cf. López, 2002, pp. 37-48)-, sino de otras formas fonético-fonológicas, morfosintácticas o léxicosemánticas típicas de tales niveles.

\section{Metodología}

El trabajo dialectal que acá presentamos se realizó a partir de las muestras tomadas por los estudiantes del curso de Sistemas fonético-fonológicos de los programas de Licenciatura en Educación Básica con énfasis en Humanidades: español-inglés y españollenguas extranjeras de la Universidad Pedagógica Nacional, entre 2009-1 y 2011-1. Aunque el trabajo elaborado por ellos fue de conocimiento básico, tales documentos se utilizaron en este estudio con el objeto de revisar los conceptos y contrastar la hipótesis planteada con anterioridad, acerca de 
la distinción $/ \mathrm{j} /$ - $/ K /$ en hablantes de la ciudad de Bogotá, Cundinamarca.

El trabajo primario consistió en una aproximación, de parte de los estudiantes, a lo que es un estudio dialectal con análisis fonético. Las instrucciones fueron: a) recolectar una muestra de habla espontánea con diversos temas (historias de miedo, anécdotas personales, relatos de accidentes, etc.), de aproximadamente 3 minutos de duración -lectura no válida-; b) escoger informantes, hombres o mujeres, de entre 15 y 65 años que hablaran de corrido - evitando aquellas personas con patologías de habla y niños pequeños-; c) realizar transliteración con análisis de suprasegmentales -acento y entonación-; d) hacer transcripción fonética estrecha y análisis de habla: clasificación dialectal y estudio de incorrecciones fonéticas y gramaticales. Todas las muestras debieron entregarse en formato compatible con Windows Media o en cinta de audio para archivar, y el trabajo impreso y legajado.

Ya para este trabajo, durante el segundo semestre de 2011 y parte del primero de 2012, realizamos varias actividades:

1. Volvimos a escuchar todas las grabaciones que se tenían en el archivo (un total de 227 muestras) y se clasificaron en dos grupos, uno de foráneos viviendo en Bogotá, y otro de bogotanos propiamente, obteniendo 80 muestras.

2. Clasificamos las muestras útiles para el trabajo en cuatro grupos etarios (GE) así: GE 1: informantes entre 15 y 30 años; GE2: informantes entre 31 y 45 años; GE3: informantes de 46 y 60 años; y GE 4: informantes de 61 años en adelante (gráfico 2). Es importante aclarar que, para cada grupo, hay repre-
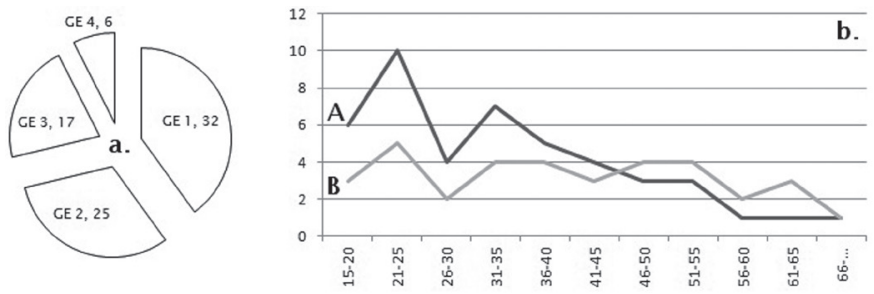

Gráfico 2 Relación de los informantes.

a. Total de informantes por grupo etario.

b. Informantes discriminados por edad y nivel educativo: alto (A) y bajo (B). sentación de dos niveles educativos: alto y bajo. El primero incluye educación media y universitaria, y el segundo, educación básica.

3. Enlistamos todos los usos de los dos fonemas en cuestión y los estudiamos haciendo identificación fonética de los segmentos utilizados y análisis espectrográfico de algunos de ellos.

4. Una vez terminado el trabajo, tabulamos los resultados de modo que se pudieran examinar las evidencias acerca de los usos reales de los fonemas $/ \mathrm{j} / \mathrm{y} / \mathrm{K} /$.

\section{Resultados}

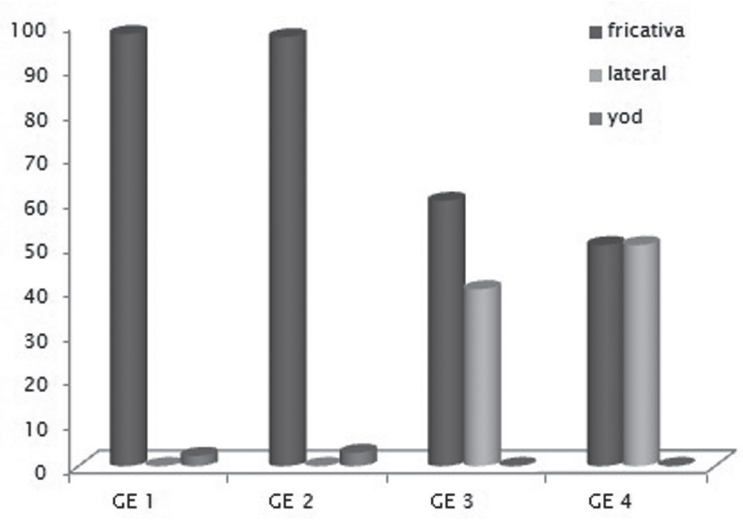

Gráfico 3. Uso porcentual observado en los cuatro grupos etarios. Generalidades

\section{Generalidades}

Luego del análisis auditivo practicado a las muestras de habla, observamos:

Uso de la /j/ o yeísmo generalizado en GE1 y GE2. No hubo distinción en cuanto a posición de los elementos $/ \mathrm{j} /$ - / $/ \mathrm{K} /$ dentro de la palabra. Además, pueden apreciarse los usos de los dos alófonos en

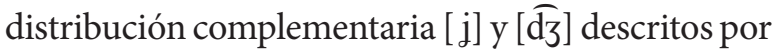
Quilis (1993, p. 275). También hay una tasa de uso de $y o d^{3}$ quivalente a 5,3\% en palabras que tienen el fonema $[y]$, independientemente de su posición; el fenómeno no se observa en palabras que tienen el fonema $/ K /$. No hay diferenciación de uso entre los dos niveles educativos que se trabajaron.

3 Término lingüístico usado para designar la semiconsonante aproximante palatal que aparece en diptongo creciente, o la semivocal palatal que aparece en diptongo decreciente. 
El GE3, tiene dos usos que marcan interés:

- Los informantes de entre 46 y 55 años aproximadamente presentan un yeísmo casi generalizado con una tasa de uso del fonema $/ K /$ de menos de un $1 \%$ en palabras que llevan la grafía $l l$; se presenta uso de yod solo en tres hablantes que han convivido con habitantes provenientes de la costa colombiana.

- Los informantes de entre 56 y 60 años aproximadamente presentan fluctuación de cerca de un 60\%, es decir, algunas veces usan $/ \mathrm{K} / \mathrm{y}$ otras, $/ \mathrm{j} /$, ante todo en palabras que llevan $l l$; es representativo tal uso en pronombres como ella y ellos y formas verbales de llegar, llamar y fallar; el uso fonético de /j/ en palabras con la grafía $y$ es normal y no se encontró presencia de yod. Sin embargo, en este GE se puede percibir diferencia en cuanto a nivel educativo pues son más fluctuantes quienes tienen un nivel bajo que quienes tienen un nivel alto $(75 \% v s .25 \%)$.

- El GE4 prefiere conservar la distinción entre la $/ \mathrm{j} / \mathrm{y}$ la $/ K /$, sin tener preferencia con el uso de la $/ K /$ o lleísmo. Solo un hablante introdujo la yod en dos palabras en las que debería usar /j/: yo y ya.

- De forma general, el uso de palabras con los sonidos /j/ y / $/$ / podría esquematizarse conforme al gráfico 3.

\section{Lectura del sonograma ${ }^{4}$ de algunas muestras}

Hacemos lectura de las imágenes de cuatro sonogramas escogidos, para ilustrar los fenómenos vinculados con ciertos usos fonéticos de la /j/ y la / $/$ / así:

1. Yeísmo: un hablante del GE1 con nivel educativo bajo.

4 Sonogramas elaborados con el programa SFS/WASP versión 1.45 (2010-12-01). Londres: Mark Huckvale University College, Department of Speech, Gearing and Phonetic Sciences. Disponible en internet en: http//www.phon.ucl.ac.uk/resource/ sfs/

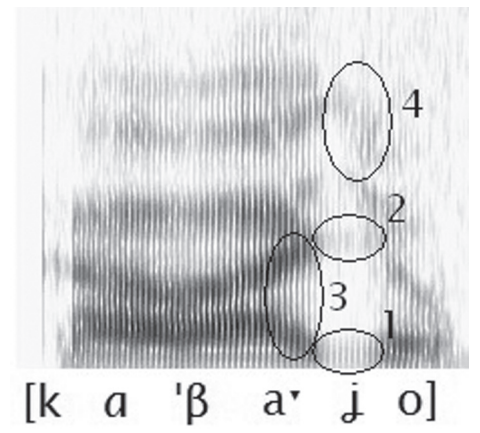

Imagen 3: Sonograma de caballo con uso del alófono fricativo.

Muestra: [ka' $\beta \mathrm{a} \cdot \mathrm{jo}]$

La presencia de una barra de sonoridad (1) que refleja un sonido consonántico sonoro (imagen 3 ). Un formante 2 muy débil en comparación con el de las vocales que lo rodean (2), señalando el rasgo de palatalidad. Luego, la lentitud en los cambios de frecuencia o transiciones formánticas (3) típicas del segmento palatal fricativo sonoro (cf. Quilis, 1988, p. 225). Y algunas señales de turbulencia presentes en el espectro por la producción de una fricativa (4).

2. Uso de yod: un hablante del GE3 con nivel educativo bajo.

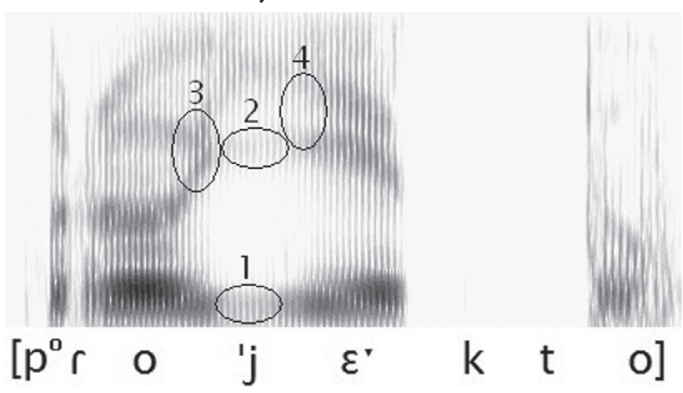

Imagen 4: Sonograma de proyecto con uso del alófono aproximante.

Muestra: [pro'jekto]

La presencia de una semiconsonante en el espectro (imagen 4) se confirma con una configuración formántica de menor intensidad que aquella de las vocales que anteceden y siguen $(1,2)$. Ello demuestra una articulación un poco más estrecha o cerrada que aquella de cualquier vocal. Las transiciones formánticas (3 y 4) entre la vocal precedente y la 
semiconsonante, y entre esta y la vocal subsiguiente son mucho más lentas que aquellas que se presentan en una relación vocal-vocal, como en los hiatos (cf. Quilis, 1988, p. 179).

3. Uso africado: un hablante de GE2 con nivel educativo alto.

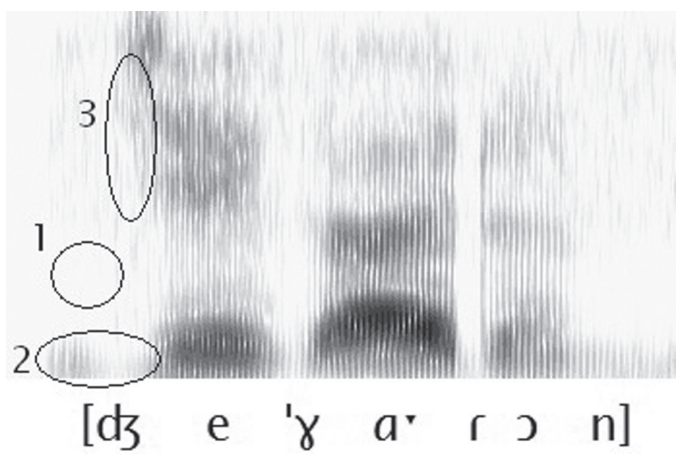

Imagen 5: Sonograma de llegaron con uso del alófono africado.

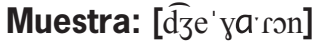

Uso africado: se evidencian dos momentos en la producción: una obstrucción y una fricatización (imagen 5). En el primer momento (1), se tiene un cierre temporal del canal fonatorio, aun habiendo vibración glotal, evidente por la presencia de la barra de sonoridad que le corresponde -más fuerte en la oclusión que en la fricción (2)-. Esta constricción es mucho mayor a la de todas las consonantes oclusivas, situación que genera la fuente del ruido turbulento del segundo momento. Así, se tiene luego de la explosión, la fricatización (3) que genera resonancia a alta frecuencia. No hay presencia clara de formantes.

4. Distinguidor: un hablante de GE4 con nivel educativo bajo.

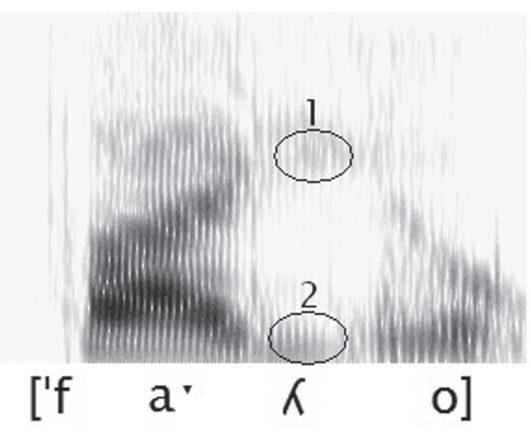

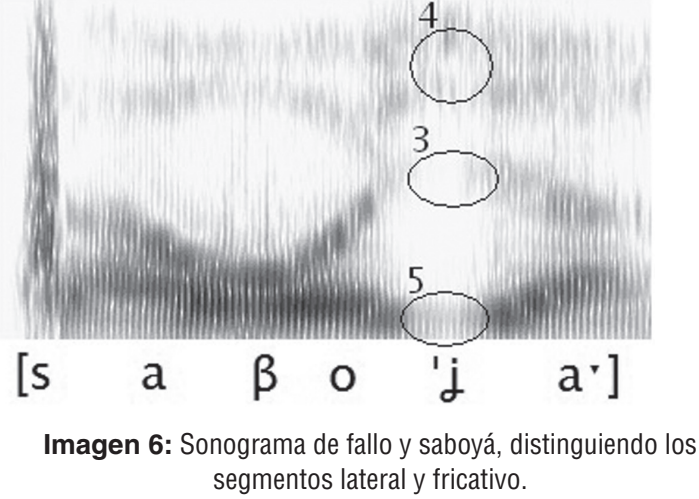

Muestra:['fa'Ko] - [saßo'ja']

El uso de cada uno de los dos segmentos palatales se diferencia claramente desde lo auditivo y desde lo espectral (imagen 6). El lateral, con unos formantes más intensos (1), muestra un primer formante (2) por debajo de aquel de las vocales que lo acompañan. El fricativo con formantes menos intensos (3), casi imperceptibles, demuestra la constricción con un leve grado de fricción (4); presenta lentitud en las transiciones y un primer formante bastante más bajo (5) que el de las vocales que lo acompañan.

\section{Conclusiones}

Después del estudio realizado a las muestras espontáneas recolectadas durante el trabajo de campo realizado por los estudiantes de la Licenciatura en Educación Básica con énfasis en Humanidades de la Universidad Pedagógica Nacional, pudimos verificar que la hipótesis planteada en la primera parte empieza a tomar bastante fuerza: "se puede percibir que el yeísmo es un fenómeno casi generalizado y que la distinción fonológica /j/ y / / / no existe más que en un delimitado número de casos".

Es evidente que en el habla bogotana, la distinción $/ \mathrm{j} / \mathrm{y} / \mathrm{K} /$ sigue perdiendo validez en la población de hasta 55 años, lo que lleva a confirmar la primera parte de la afirmación pues corroboramos que es un fenómeno casi generalizado. Además, como pudimos comprobarlo, de esta edad hasta los 60 años se presenta una fluctuación en el uso, señalando que la pérdida total de la distinción se encuentra en esta generación.

De otro lado está el uso pertinente de dichos fonemas en mayores de 60 años. Los resultados no 
confirman totalmente la segunda parte de la aseveración citada, porque este grupo poblacional no es tan delimitado en Bogotá, sino que llega aproximadamente a las 565.000 personas (cf. DANE, pp. 59-60), sin embargo, sí deja notar la probabilidad de que la distinción no será pertinente por más de 50 o 60 años.

Resta examinar el uso en raizales ubicados en las zonas rurales para establecer si la lejanía a la urbe y a otras gentes, ha dejado pervivir el uso sobre todo en las nuevas generaciones. Asimismo, sería interesante hacer un estudio con una cantidad mucho mayor de informantes, aplicando algunas metodologías sociolingüísticas y estadísticas que permitan llegar a conclusiones más determinantes.

\section{Referencias bibliográficas}

Aráus, C. (2005). Manual de lingüística hispanoamericana: El español en la metrópoli. Series Minor, XLII. Bogotá: Instituto Caro y Cuervo.

Caro, M. A. (1972). Obras. Tomo II. Bogotá: Instituto Caro y Cuervo.

Constenla, A. (1984). Los fonemas del muisca. En: M. Peña y A. Constenla (eds). Estudios de lingüística chibcha (pp. 65-111). Serie A, 3. San José de Costa Rica: Programa de investigación del Departamento de Lingüística de la Universidad de Costa Rica.

Cuervo, R. (1955). Apuntaciones críticas sobre el lenguaje bogotano. 9a. ed. Bogotá: Instituto Caro y Cuervo.

Departamento Administrativo Nacional de Estadística (2010). Censo General 2005: perfil municipal de Bogotá. Boletín del Bicentenario de la Independencia de Colombia 1810-2010. Bogotá.

Espejo, M.B. (2005). El español bogotano: una lengua de prestigio. Revista La Tadeo, 71, 203-209.

Espejo, M.B. (abril de 1999). Observaciones sobre fonética segmental del habla culta de Bogotá. Litterae, $8,68-86$.

Flórez, L. (1963). Lecciones de pronunciación: adaptadas a los programas de español y literatura para la educación media. Bogotá: Instituto Caro y Cuervo.

Flórez, L. (1973). Las "apuntaciones críticas" de Cuervo y el español bogotano cien años después: pronunciación y fonética. Series Minor, XVI. Bogotá: Instituto Caro y Cuervo.

Flórez, L. (1978). Sobre algunas formas de pronunciar muchos colombianos el español. Thesaurus, 33, 198-246.

Fundación Foro Nacional por Colombia (octubre de 2006). Foro debates 5: pobreza y exclusión Social en Bogotá, Medellín y Cali. Bogotá.

González de Pérez, M.S. (1980). Trayectoria de los estudios sobre la lengua chibcha o muisca. Series Minor, XXII. Bogotá: Instituto Caro y Cuervo.
González de Pérez, M.S. (1987). Diccionario y gramática chibcha. Biblioteca Ezequiel Uricoechea. Bogotá: Instituto Caro y Cuervo.

Guitarte, G. (1983). Notas para la historia del yeísmo (pp. 127-146). Siete estudios sobre el español de América. México: Centro de Lingüística Hispánica.

Jakobson, R. y Halle, T. (1980). Fundamentos del lenguaje. 3a. ed. Madrid: Editorial Ayuso.

Lapesa, R. (2008). Historia de la lengua española. Madrid: Gredos.

Lleal, C. et al. (2000). Historia de la lengua española. Barcelona: Ediciones de la Universitat de Barcelona.

Lipski, J. (1994). El español de américa. Madrid: Cátedra.

Lozano, M. (1998). El habla de bogotá: ¿Qué palabras usa el hablante de estratos alto, medio y bajo? Thesaurus, 53(3), 735-737.

López, A.M. (2002). Sociolingüística de los medios de comunicación. Linguistik Online, 12, 3/02. [En línea]. Recuperado el 11 de noviembre de 2012 de: http:// www.linguistik-online.de/12_02/lopez.pdf

Montes, J.J. (1963). ¿Desaparece la $l l$ de la pronunciación bogotana? Thesaurus, 24, 102-104.

Montes, J.J. (1965). Contribución a una bibliografía de los estudios sobre el español de Colombia. En: Thesaurus, 20, 425-265.

Montes, J.J. (1975). Breves notas de fonética actual del español. Thesaurus, 33, 338-340.

Montes, J.J. (1976). Breve esbozo del ALEC: desarrollo, enseñanzas, resultados probables. Revista de Letras, $18,185-194$.

Montes, J.J. (1985). El español bogotano en 1983. Thesaurus, 40, 293-307.

Montes, J.J. (1985). Estudios sobre el español de Colombia. Bogotá: Instituto Caro y Cuervo.

Montes, J.J. (1985). Sobre estudios de fonética del español de Colombia. Thesaurus, 60, 396-400

Montes, J.J. (1992). El español hablado en Colombia. En: C. Hernández (coord.). Historia y presente del español de América (pp. 519-542). Madrid: Junta de Castilla y León.

Montes, J.J. (1995). Dialectología general e hispanoamericana: orientación teórica, metodológica y bibliográfica. Bogotá: Instituto Caro y Cuervo.

Montes, J.J. (2000). Otros estudios sobre el español de Colombia. Bogotá: Instituto Caro y Cuervo.

Moreno de Alba, J. (1988). El español en América. México: Fondo de Cultura Económica.

Navarro, T. (1964). El yeísmo en España. Thesaurus, 19, $1-17$.

Ocampo, J. (1978). Historia básica de Colombia. Bogotá: Plaza y Janés Editores.

Quilis, A. (1993). Tratado de fonología y fonética españolas. Madrid: Gredos.

Quilis, A. (1988). Fonética acústica de la lengua española. Madrid: Gredos. 